\title{
. \\ VARIOUS MANIFESTATIONS OF WEAK MAGNETISM AND SUPERCONDUCTIVITY IN INCLINATION INTERFACES OF Bi, Sb AND Bi $i_{1-\mathrm{x}} \mathbf{S b}_{\mathrm{x}}$ $(0.07 \leq x \leq 0.2)$ ALLOYS
}

\author{
Fiodor M. Muntyanu, ${ }^{1}$ Konstantin Nenkov ${ }^{2}$, Andrzej J. Zaleski ${ }^{3}$, Elena Condrea ${ }^{1}$, and \\ Vitalie Chistol $^{4}$ \\ ${ }^{1}$ D. Ghitu Institute of Electronic Engineering and Nanotechnologies, Chisinau, MD-2028 \\ Republic of Moldova \\ ${ }^{2}$ Leibniz-Institut fur Festkorper und Werkstofforschung, Dresden, 01171 Germany \\ ${ }^{3}$ Institute of Low Temperatures and Structural Research, Polish Academy of Sciences, Wroclaw, \\ 50950 Poland \\ ${ }^{4}$ Technical University of Moldova, Chisinau, MD-2004 Republic of Moldova \\ E-mail: muntean_teodor @yahoo.com)
}

(Received June 10, 2021)

https://doi.org/10.53081/mjps.2021.20-2.03

CZU:538.945+537.622+546.86/.87

\begin{abstract}
The magnetic properties of the nano-width bicrystal interfaces (CIs) of Bi, Sb and 3D topological insulator $\mathrm{Bi}_{1-x} \mathrm{Sb}_{x}(0.06 \leq x \leq 0.2)$ are studied in a temperature range of $1.6-300 \mathrm{~K}$. These materials do not show superconductivity under normal rhombohedral conditions and are anomalous diamagnetics. At the same time, two superconducting phases with $T_{\mathrm{c}} \leq 21 \mathrm{~K}$ and magnetic hysteresis loops against a diamagnetic background typical for strong type II superconductors are identified in Bi interfaces. At the CIs of $\mathrm{Bi}_{1-x} \mathrm{Sb}_{x}(0.06 \leq x \leq 0.2)$, as well as $\mathrm{Sb}$, a superconducting transition and a ferromagnetic hysteresis loop or a dual loop (superimposed ferromagnetic and superconducting loops) against a paramagnetic background are observed; they indicate the simultaneous occurrence of superconductivity and weak ferromagnetism, which is specific to $3 \mathrm{D}$ topological insulators. The revealed coexistence of superconductivity and weak magnetism at these CIs is of significant interest for the fundamental physics and future applications in quantum computing and spintronic devices.

Keywords: bismuth, antimony, bismuth-antimony alloys, bicrystal interface, superconductivity and ferromagnetism, 3D topological insulator
\end{abstract}

\section{Rezumat}

Proprietățile magnetice ale interfețelor bicristaline (CIs) de nano-lățime din $\mathrm{Bi}, \mathrm{Sb}$ și 3D izolator topologic $\mathrm{Bi}_{1-\mathrm{x}} \mathrm{Sb}_{\mathrm{x}}(0,06 \leq \mathrm{x} \leq 0,2)$ au fost studiate în intervalul de temperatură $1.6-300 \mathrm{~K}$. Aceste materiale nu prezintă supraconductibilitate în condiții romboedrice normale şi sunt diamagnetici anormali. În același timp, două faze supraconductoare cu $T_{c} \leq 21 \mathrm{~K}$ și bucle de 
istereză magnetică pe un fundal diamagnetic tipic pentru superconductorii puternici de tip II au fost identificate în interfețele $\mathrm{Bi}$. În CIs ale $\mathrm{Bi} 1-\mathrm{xSbx}(0,06 \leq \mathrm{x} \leq 0,2)$, precum și ale Sb s-au observat tranziții supraconductoare și bucle de istereză feromagnetică sau bucle duale (bucle feromagnetice și de tip supraconductor suprapuse) pe un fundal paramagnetic, indicând prezenţa simultană a supraconductivității și feromagnetismului slab, specificâ izolatorilor topologici 3D. Coexistența supraconductivităţii și a magnetismului slab in aceste CIs manifestă un interes sporit pentru fizica fundamentală și aplicațiile viitoare în computing cuantic și dispozitive spintronice.

Cuvinte cheie: bismut, stibiu, aliaje bismut-stibiu, interfață bicristalină, superconductivitate și ferromagnetism, izolator topologic 3D

\section{Introduction}

The $\mathrm{Bi}, \mathrm{Sb}$, and their solid solutions $\mathrm{Bi}-\mathrm{Sb}$ show anomalous diamagnetism and have long played a very important role in solid state physics. The electronic structure of rhombohedral single crystals of both semimetals $\mathrm{Bi}$ and $\mathrm{Sb}$ is characterized by a weak overlapping of the valence and conduction bands. These materials have a metallic outer surface with fairly similar electronic structures $[1,2]$. An increase in the Sb content $x$ in Bi leads to the removal of the band overlap, so that the $\mathrm{Bi}_{1-x} \mathrm{Sb}_{x}$ alloys in a concentration range of $0.07 \leq x \leq 0.2$ become narrow-gap semiconductors with an inverted (from $x \approx 0.04$ ) symmetry ordering of bands at L points. According to [1-3], $\mathrm{Bi}_{1-x} \mathrm{Sb}_{x}(0.07 \leq x \leq 0.2)$ alloys are strong 3D topological insulators (TIs) with $\mathrm{Z}_{2}$ invariant $v_{0}=1$ [1], such as for antimony. For Bi the topological invariant $v_{0}=0$, so that $\mathrm{Bi}, \mathrm{Sb}$, and $\mathrm{Bi}-\mathrm{Sb}$ alloys substantially differ in topology.

The topological situation entirely changes in the bicrystal interfaces (CIs) with an isolated growing wall of dislocations and a high degree of perfection. These interfaces are more available in experiment than other low-dimensional nanoobjects. In addition, by varying the crystallite disorientation angle, it is possible to change the charge carrier concentration, the number of microstructural defects, and the stress states, which finally highlight new features of several physical phenomena.

\section{Experimental}

The inclination bicrystals of $\mathrm{Bi}, \mathrm{Sb}$, and $\mathrm{Bi}_{1-x} \mathrm{Sb}_{x}(0 \leq x \leq 0.2)$ alloys $\left(1 \times 2 \times 4 \mathrm{~mm}^{3}\right)$ consisting of two crystallites with crystallographic axes revolved in a single plane and nanowidth CIs (see Fig. 1a) were prepared by the horizontal zone recrystallization method using the double seed technique. The composition of the bicrystals and magnetic impurity concentration was controlled by scanning electron microscopy (SEM), neutron activation analysis, and optical emission spectrometry methods.

The width of interfaces was estimated by SEM (see Figs. 1b-1d), by measurements of the superconducting parameters, and from quantum oscillations [3]. It was found that $\mathrm{CIs}$ of $\mathrm{Bi}, \mathrm{Sb}$, and $\mathrm{Bi}-\mathrm{Sb}$ alloys have a width of $\sim 100 \mathrm{~nm}$ and consist of a solitary central part of $\sim 60 \mathrm{~nm}$ and two similar adjacent layers $\sim 20 \mathrm{~nm}$ thick each on both sides of it. 


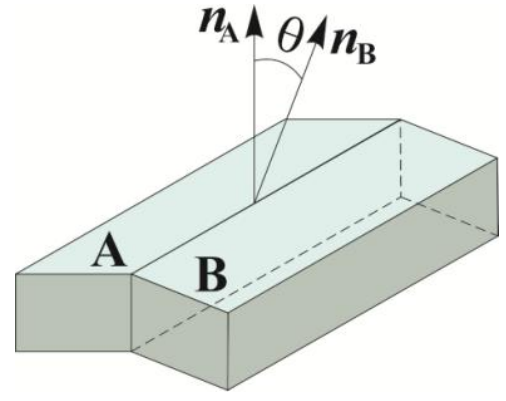

a)

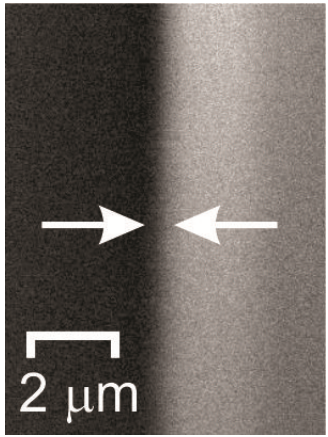

b)

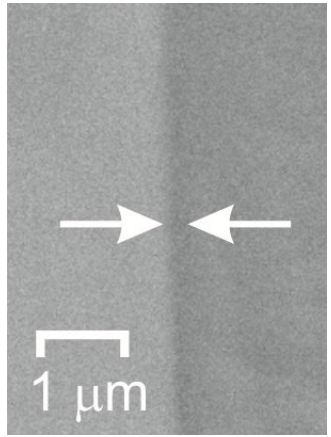

c)

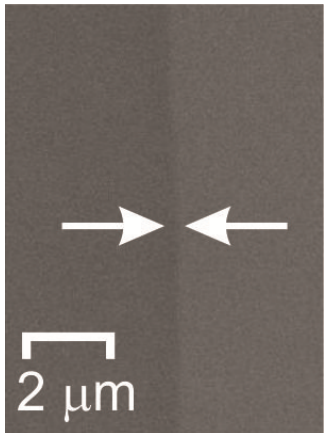

d)

Fig. 1. (a) Inclination bicrystal: $\theta$, relative $C I$ disorientation angle, $A$ and $B$ are crystallites; (b, c, d) SEM images of $\mathrm{Bi}, \mathrm{Sb}$, and $\mathrm{Bi}-\mathrm{Sb}$ bicrystals, respectively. The arrows indicate the $\mathrm{CI}$ location.

\section{Results and Discussion}

\subsection{Bismuth interfaces}

Some unusual results were detected in Bi CIs [3]: new high-frequency $\mathrm{SdH}$ quantum oscillations, pronounced longitudinal Hall quasi-plateaus $(\sim 3, \sim 6, \sim 15 \mathrm{~T})$, and finally the discovery of CIs superconductivity.

Figure 2 shows typical temperature and field dependences of magnetic moment $m$ of $\mathrm{Bi}$ bicrystals. One or two superconducting transitions associated with CIs are observed: the first lowtemperature phase with $T_{\mathrm{c}} \leq 4.3 \mathrm{~K}$ assigned to the adjacent layers and the second transition to slightly higher temperatures $\left(8.4 \mathrm{~K} \leq T_{\mathrm{c}} \leq 21 \mathrm{~K}\right)$ attributed to the central layer. According to [3], the superconductivity of the $\mathrm{Bi}$ interfaces results from the reconstruction of the rhombohedral crystal structure A7 under deformations. In this case, the topology of isoenergetic surfaces is modified and the phonon spectra at CIs change stimulating an electron pair correlation. The superconductivity of nano-width CIs with $T_{\mathrm{c}} \leq 21 \mathrm{~K}$ is an unusual event, because bismuth bulk single crystals do not exhibit superconductivity down to ultra-low temperatures.

The results shown in Fig. 2a also reveal that the hysteresis loops of Bi bicrystals unfold against a diamagnetic background and do not significantly change their form with temperature. The ZFC and FC dependences (see Fig. 2b, inset) denote a considerable diamagnetic Meissner signal, a pronounced magnetic flux expulsion, and the superconducting transition starting off at $36 \mathrm{~K}$, which is in good agreement with specific heat data [4]. 

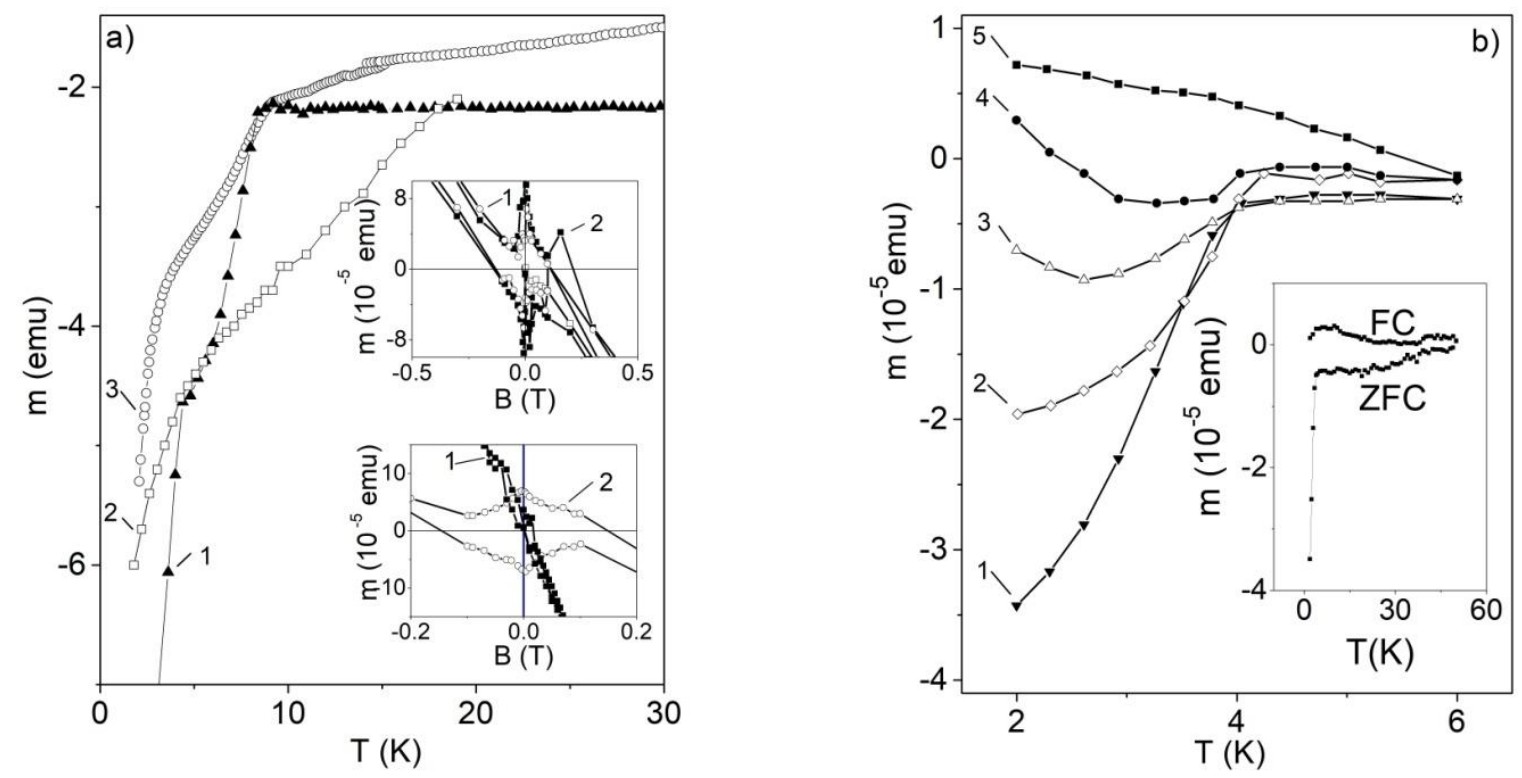

Fig. 2. Magnetic moment versus temperature $T$ and magnetic field $B$ for Bi bicrystals: (a) $\theta=(1) 4^{\circ}$, (2) $5^{\circ}$, and (3) $4.5^{\circ}$; the upper inset: $\theta=4^{\circ}$ at (1) 2.1 and (2) $6 \mathrm{~K}$; the lower inset: $2.1 \mathrm{~K}, \theta=(1) 5^{\circ}$ and (2) $2^{\circ}$; (b) temperature dependences $m(T)$ in a magnetic field: $\theta=5^{\circ}$, (1) 0.005 , (2) 0.01 , (3) 0.02 , (4) 0.04, (5) and $0.08 \mathrm{~T}$; the inset: FC and ZFC curves in a bicrystal with $\theta=4.5^{\circ}$.

\subsection{Interfaces of $3 D$ TI Bi $i_{1-x} S b_{x}(0.06 \leq x \leq 0.2)$}

The CIs of $\mathrm{Bi}_{1-x} \mathrm{Sb}_{x}(0.07 \leq x \leq 0.2)$ alloys are characterized [3-5] by several unusual features: the detection of a semiconductor-semimetal transition in CIs layers at different magnetic field value, the occurrence of superconductivity and weak ferromagnetism at component layers of interfaces, etc.

Figures $3 \mathrm{a}-3 \mathrm{c}$ show hysteresis loops and temperature dependences of both magnetic moment $m(T)$ and $\mathrm{AC}$ susceptibility $\chi^{\prime}(T)$ of $\mathrm{Bi}_{1-x} \mathrm{Sb}_{x}(0.07 \leq x \leq 0.2)$ inclination bicrystals. It is found that the hysteresis loops are similar to those of strong type-II superconductors against a diamagnetic background or those of weak ferromagnetic materials against a paramagnetic background. Moreover, a number of interfaces at $T<10 \mathrm{~K}$ with a higher carrier density and one (see Fig. 3a, lower inset) or two superconducting transitions (see Fig. 3c, inset) exhibit either a ferromagnetic hysteresis loop against a paramagnetic background or a dual loop, i.e., a ferromagnetic and a superimposed superconducting hysteresis loop [5].

The $m(T)$ and $\chi^{\prime}(T)$ dependences were used to determine the zero temperature coherence length $\xi$ and the superconducting layers thickness $d$ of CIs with hysteresis loops against a paramagnetic background. The following values were obtained (in nm): $\xi \approx 30-35, d \approx 100-120$ (for a single superconducting transition) and $\xi_{1} \approx 11-13, d_{1} \approx 27-32, \xi_{2} \approx 17-19, d_{2} \approx 59-66$ (for two superconducting transitions), whereas at single-phase superconducting interfaces, the $\xi$ and $d$ parameters are almost three times higher than those for the first phase of two-phase superconducting CIs. All these manifestations show that the superconductivity and 
ferromagnetism in 3D TI CIs can be considered as competing ordering phenomena at the entire interfaces.

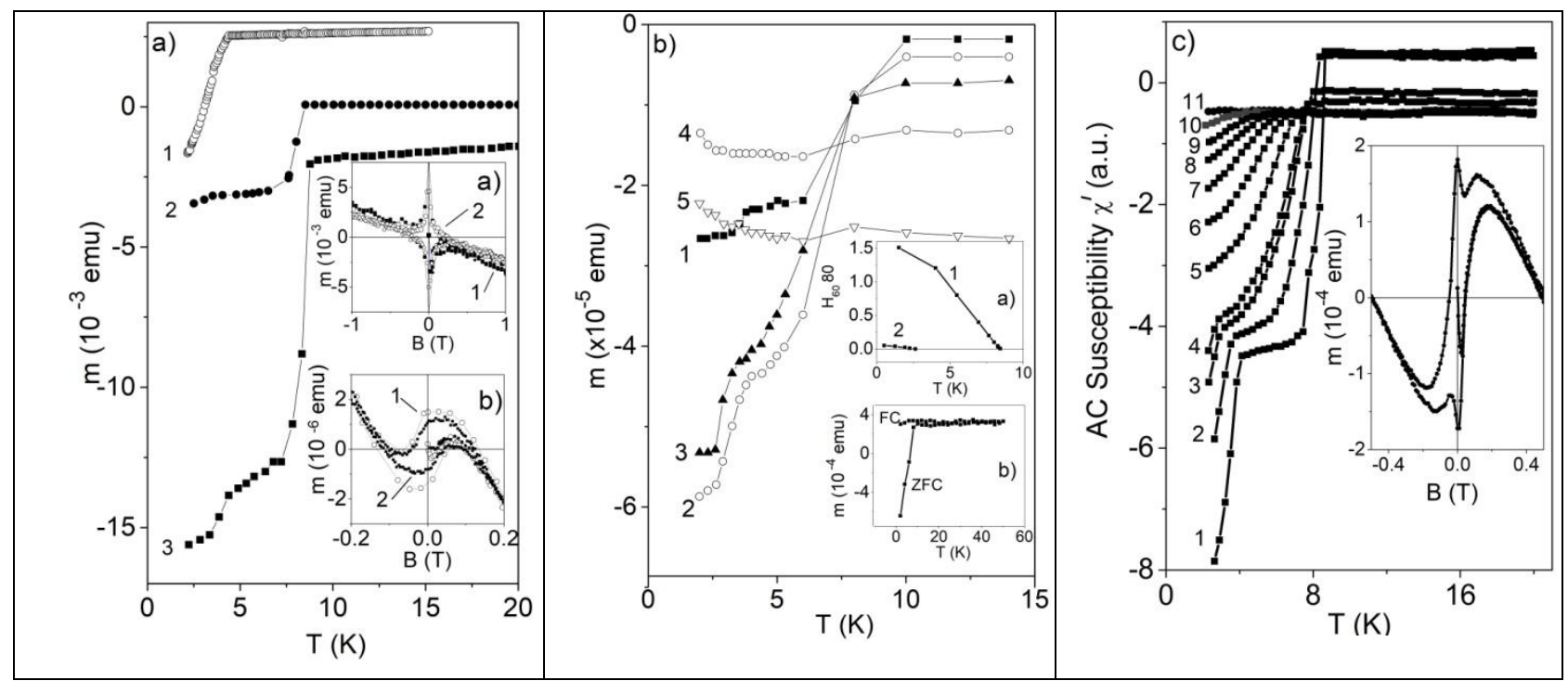

Fig. 3. Magnetic moment and real part of the $\mathrm{AC}$ susceptibility for $\mathrm{Bi}_{1-x} \mathrm{Sb}_{x}(0.07 \leq x \leq 0.2)$ bicrystals: (a) (1) $\mathrm{Bi}_{0.94} \mathrm{Sb}_{0.06} \mathrm{Te}, \theta=9^{\circ}$, (2) $\mathrm{Bi}_{0.85} \mathrm{Sb}_{0.15}, \theta=14^{\mathrm{o}}$, and (3) $\mathrm{Bi}_{0.94} \mathrm{Sb}_{0.06} \mathrm{Te}, \theta=4.6^{\mathrm{o}}$; the upper inset: magnetic hysteresis loop, $\mathrm{Bi}_{0.93} \mathrm{Sb}_{0.07} \mathrm{Sn}, \theta=4.6^{\circ}$ at 2 and $5 \mathrm{~K}$; the lower inset: magnetic hysteresis loop, $\mathrm{Bi}_{0.85} \mathrm{Sb}_{0.15}, \theta=14^{\circ}$ at 2 and $10 \mathrm{~K}$; (b) $\mathrm{Bi}_{0.85} \mathrm{Sb}_{0.15}, \theta=4^{\circ}, B=(1) 0.005$, (2) 0.01 , (3) 0.02 , (4) 0.04 , and (5) $0.08 \mathrm{~T}$; the upper inset: the upper critical field $B_{\mathrm{c} 2}(T),(1)$ the first superconducting phase, (2) the second superconducting phase; the lower inset: $\mathrm{ZFC}$ and $\mathrm{FC}$ curves, $\mathrm{Bi}_{0.85} \mathrm{Sb}_{0.15}, \theta=15^{\circ}$; and (c) $\mathrm{Bi}_{0.85} \mathrm{Sb}_{0.15} \mathrm{Sn}, \theta=19^{\circ}, B=$ (1) 0, (2) 0.04, (3) 0.15, (4) 0.2, (5) 0.4, (6) 0.6, (7) 0.8, (8) 1, (9) $1.2,(10) 1.5$, and (11) $2 \mathrm{~T}$; the inset: magnetic hysteresis loops at $1.8 \mathrm{~K}$.

The ZFC and FC curves show the onset of the superconducting transition of small disorientation angle (SDA) interfaces $T_{\text {onset }} \leq 36 \mathrm{~K}$, while in bicrystals with $\theta \geq 25^{\circ}$ they branch at temperatures below $10 \mathrm{~K}$ due to an increase in disorder density.

\subsection{Antimony interfaces}

Antimony exhibits characteristics of a strong 3D TI [6], does not exhibit superconductivity or ferromagnetism; however, the occurrence of a metallic topologically protected surface state with a single Dirac cone and topological nontrivial-to-trivial transitions under the action of external factors was revealed [7].

The studied $\mathrm{Sb}$ interfaces exhibit a single superconducting transition with $6.5 \mathrm{~K} \leq T_{\mathrm{c}} \leq 10$ $\mathrm{K}$ [8]. Figures $4 \mathrm{a}$ and $4 \mathrm{~b}$ show the $m(T)$, real $\chi^{\prime}(T)$ dependences and imaginary $\chi^{\prime \prime}(T)$ parts of AC susceptibility in a magnetic field directed along the interface plane. It was found that the upper critical field $B_{\mathrm{c} 2}(T)$ is linear in a wide temperature range; this finding made it possible to estimate a number of important parameters of SDA CIs. For example, bicrystal interfaces with $\theta=5^{\circ}$ and $T_{c} \sim 6.5 \mathrm{~K}$ denote the $d B c_{2} / d T \sim 0.04 \mathrm{~T} / \mathrm{K}, B_{c 2}(0) \sim 0.18 \mathrm{~T}$, and coherence length of $\xi(0) \sim$ $43 \mathrm{~nm}$, which is slightly higher than that of $\mathrm{Bi}_{1-x} \mathrm{Sb}_{x}(0.07 \leq x \leq 0.2)$ CIs. The real and imaginary parts of AC susceptibility show that, if the CIs temperature approaches $T_{\mathrm{c}}$, a single abrupt drop 
occurs in $\chi^{\prime}(T)$ and a peak in $\chi^{\prime \prime}(T)$ simultaneously appears, which means the presence of a single superconducting phase.
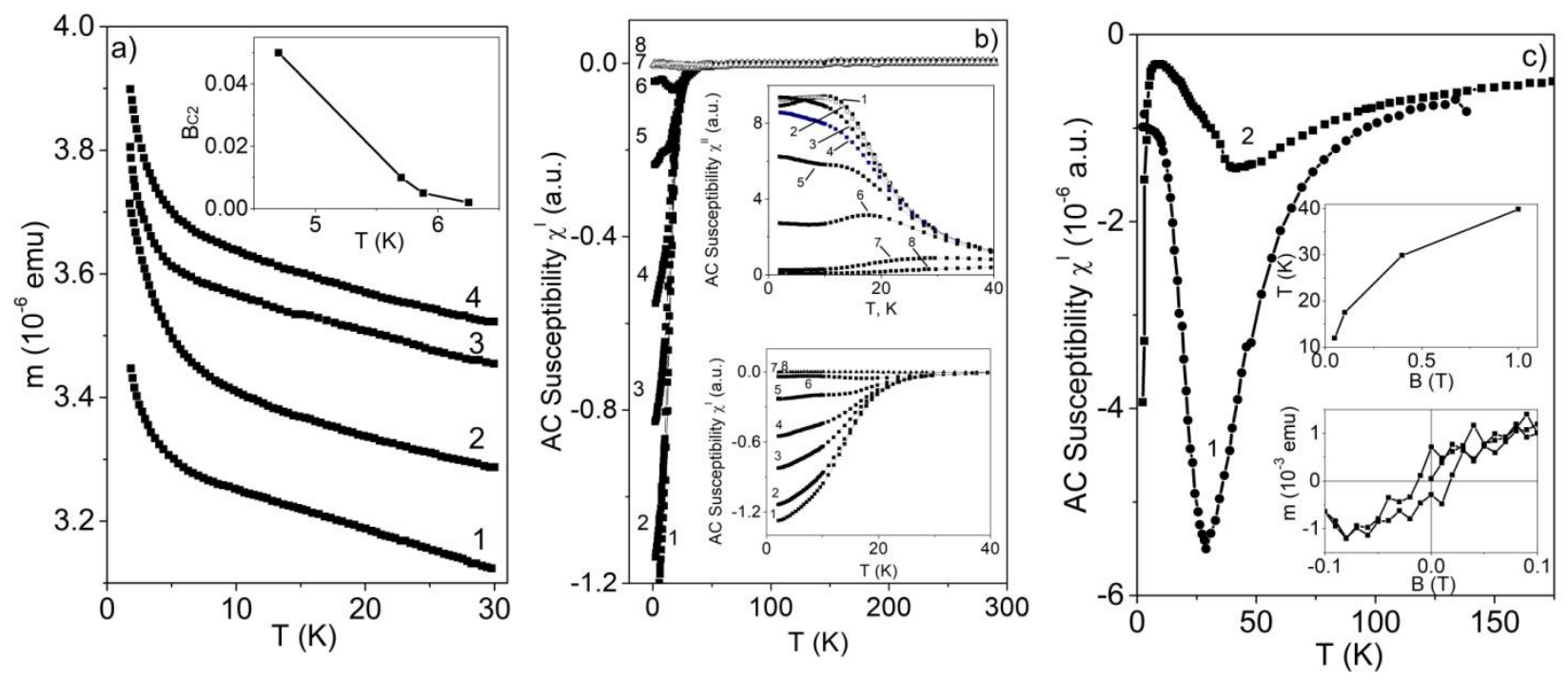

Fig. 4. Magnetic moment and AC susceptibility versus temperature for Sb bicrystals: (a) $\theta=5^{\circ}$, (1) 0.002 , (2) 0.005 , (3) 0.01 , and (4) $0.05 \mathrm{~T}$, the inset show the $B_{\mathrm{c} 2}(T)$ dependences; (b) $\theta=2^{\circ}, f=1000$ Hz: (1) 0, (2) 0.01, (3) 0.02, (4) 0.03, (5) 0.05, (6) 0.1, (7) 0.4, and (8) $1 \mathrm{~T}$; and (c) $\theta=2^{\circ}, f=1000$ Hz: (1) 0.4 and (2) $1.0 \mathrm{~T}$, the upper inset shows the temperature dependences of $\chi^{\prime}(T)$ maximum at different applied fields, the lower inset shows magnetic hysteresis loops at $2 \mathrm{~K}$.

The $\chi^{\prime \prime}(T)$ data indicate the energy dissipation in CIs region; however, the applied field suppresses superconductivity and pushes the onset of superconducting transition to lower temperature. The $m(B)$ dependences of Sb CIs show ferromagnetic hysteresis loops against a paramagnetic background (see the lower inset in Fig. 4c). On the contrary, in bicrystals with slightly larger disorientation angles at $T>25 \mathrm{~K}$, a diamagnetic maximum of $\chi^{\prime}(T)$ at $B \geq 0.4 \mathrm{~T}$ appears, which is suppressed and shifted to higher temperatures (see the upper inset in Fig. 4c) due to the spin reorientations of charge carriers.

\section{Conclusions}

The magnetic and superconducting properties of high-quality bicrystals of $\mathrm{Bi}, \mathrm{Sb}$, and $3 \mathrm{D}$ $\mathrm{TI} \mathrm{Bi}_{1-x} \mathrm{Sb}_{x}(0.06 \leq x \leq 0.2)$ have been studied. The superconducting transitions (one or two) with $T_{\mathrm{c}}$ up to $21 \mathrm{~K}$ have been reliably recorded in SDA CIs of these materials. At the same time, the magnetic hysteresis loops against a diamagnetic background typical for strong type II superconductors have been detected at interfaces of $\mathrm{Bi}$ and some $\mathrm{CIs}$ of 3D TI Bi-Sb bicrystals. At inclination interfaces of $\mathrm{Sb}$ and in a number of 3D $\mathrm{TI} \mathrm{Bi}-\mathrm{Sb} \mathrm{CIs}$, either a ferromagnetic hysteresis loop against a paramagnetic background or a dual loop (ferromagnetic and a superimposed superconducting loop) have been registered; this fact indicates the simultaneous occurrence of superconductivity and weak ferromagnetism. 


\section{References}

[1] L. Fu and C. L. Kane, Phys. Rev. B76, 045302 (2007).

[2] D. Hsieh, D. Qian, 1. Wray, Y. Xia, Y. Hor, R. J. Cava, and M. Z. Hasan, Nature (London) 452, 970 (2008).

[3] F. M. Muntyanu, A. Gilewski, K. Nenkov, A. Zaleski, and V. Chistol, Phys. Rev. B 76, 014532 (2007).

[4] F. M. Muntyanu, A. Gilewski, K. Nenkov, A. Zaleski, and V. Chistol, Phys. Status Solidi B 248 (12), 2903 (2011).

[5] F. M. Muntyanu, A. Gilewski, A. J. Zaleski, V. Chistol, and K. Rogacki, Phys. Lett. A 381, 2040 (2017).

[6] M. G. Blamire and J. W. A. Robinson, J. Phys.: Condens. Matter 26, 453201 (2014).

[7] D. Hsieh, Y. Xia, L. Wray, D. Qian, A. Pal, J. H. Dil, J. Osterwalder, F. Meier, G.. Bihlmayer, C. L. Kane, et al., Science 323, 919 (2009).

[8] F. M. Muntyanu, K. Nenkov, A. J. Zaleski, N. Muntean, and V. Chistol, Solid State Comm. 299, 113660 (2019). 